\title{
The Aesthetics of Protest in UK Rave
}

\author{
RAMZY ALWAKEEL \\ INDEPENDENT SCHOLAR
}

\begin{abstract}
Informed by the conceptualisation of an "aesthetic politics" around largely unlawful rave and dance scenes in Britain between the late-1980s and mid-1990s, this article explores negotiations between these EDMCs and the British Parliamentary and legal establishments. Two case studies will inform the argument that rave culture effects a "performative protest". That is, Autechre's response to the 1994 Criminal Justice and Public Order Act and the work of The Justified Ancients of Mu Mu in the late-1980s will be discussed in order to suggest that rave can be considered a speech-act that immediately communicates its own refusal to submit to authority. It will be suggested that rave's responses to power structures derive from the internal dynamics of its own aesthetic politics. I shall conclude that rave has often functioned as a potent political vehicle on its own terms, but that the embrace of its own multiplicity safeguards it against exhaustion by any single agenda.
\end{abstract}

\section{Keywords}

rave, politics, aesthetics, Autechre, JAMs

"Music" includes sounds wholly or predominantly characterised by the emission of a succession of repetitive beats.

Criminal Justice and Public Order Act 1994: section 63, subsection $1 \mathrm{~b}$

Warning: Lost and Djarum contain repetitive beats. We advise you not to play these tracks if the Criminal Justice Bill becomes law. Flutter has been programmed in such a way that no bars contain identical beats and can therefore be played at both forty five and thirty three revolutions under the proposed new law. However, we advise DJs to have a lawyer and a musicologist present at all times to confirm the non repetitive nature of the music in the event of police harassment.

Autechre, sleevenotes to the Anti EP, 1994

The UK's notorious Criminal Justice and Public Order Act of 1994 furnished the British legal establishment with new powers to prevent people from playing dance music during the night at "gathering[s] on land in the open air of 100 or more persons". Autechre's tongue-in-cheek response put its money where its mouth was: all 
proceeds from the record's sales went to the National Council for Civil Liberties, while a sticker on the 12-inch sleeve warned that the Act sought "to outlaw diversity and dissent" and to target "specific groups of people in an unjust and discriminatory way".

Despite the directness of these particular protestations, Autechre's usual public relations are determinedly opaque. Nowhere else in their sizeable catalogue is there so much as a complete sentence: their album and track titles range from abstract to incomprehensible; their artwork eschews any visual representation of Autechre themselves; their records are entirely instrumental. This absence of voice is not unusual amongst dance artists: subjectivity within EDMCs is often shifting or multiple, more so than in the idealised brush strokes of rock music. ${ }^{1}$ Jimmy Cauty and Bill Drummond, for example, have established semi-distinct artistic identities as The Justified Ancients of $\mathrm{Mu} \mathrm{Mu}$, The KLF and The Timelords, all deeply critical of the process that generates marketable musical figureheads. Elsewhere, under names such as The Aphex Twin, AFX and Polygon Window, Richard D. James has exploded conventional ideas about the creative subject through a complex manipulation of the artistic strands - name, appearance, voice, style - usually taken to signify the self. Against this backdrop, Autechre's response to the Criminal Justice Act is problematic: it looks like a statement of political protest, but who is making it, and on what grounds?

To address these questions, the "political" itself must be appraised and defined. Following this, the present work will focus upon the British rave and dance scenes between the late-1980s and the mid-1990s (for brevity, hereafter referred to as "rave", although the shortcomings of the singular will be noted), assessing the applicability of each analysis to the EDMCs in question. A further idea will be acknowledged: that these scenes were devoid of objective, only being perceived as subversive at all because the government treated their apparatus as such. It will be argued, however, that this lack of object does not silence rave on all counts; on the contrary, a specific political currency lies precisely in its very persistence in the face of regulation. To develop the argument, I will attempt to formulate an "aesthetic politics" of rave that derives from the culture's internal relationships: those between subject and object, between content and form, especially where these divisions are shown to be problematic or inadequate. This will be used to inform an understanding of rave's relationships to the external world. As a key component of these relationships, I will propose that rave's response to external pressures is performative: that, as an effect of these aesthetic politics, rave's very existence can be seen to function as a speech-act.

This theory of performative protest will be explored within two case studies: the Autechre EP mentioned above, whose active use contravenes the Act to which it objects, and The Justified Ancients of $\mathrm{Mu} \mathrm{Mu}$, who use unlicensed samples to critique the notion that sound can be owned.

\section{Protest and power}

Popular music has made extensive comment on the relationships between government and citizens. Musicians across a variety of disciplines frequently address issues such as war, human rights and the state through lyrics and sleevenotes. The role of music within social and cultural movements has been considered at length by critics and journalists. Peter Doggett (2007) and Reebee Garofalo (1992), for example, refer to numerous examples of popular musicians committed to cultural politics through public speaking or lyrical content. While "protest music" in the context, for instance, of 
rock is often characterised by vocal opposition to oppression through song, the acts of protest explored within this article take place through primarily non-verbal means. This is, in part, due to the music itself; EDM is often either completely instrumental or laden with samples in such a way that it is difficult to differentiate "words" from "sounds", or "voice" from "instrument". Music that does not contain explicitly oppositional lyrics might instead function as "protest" through projects and events: that is, through its use. Such events might be aimed, for instance, to promote awareness, or raise funds. More fundamentally, however, it is argued that the very act of raving, or the very existence of rave events and music, can be considered a form of protest.

In an attempt to understand "protest" in this context, I begin with the central argument in Robin Balliger's piece "Politics": that music's political currency lies not just in its lyrical content but in the modes of its use. Integral to her study is a case for the expansion of the term "politics" to include "not only state and economic structures but also power relations in everyday life" (Balliger 1999: 59). Balliger suggests that social power structures may be reinforced or resisted by popular music, but that these cultural effects are determined by the process of consumption: music's "meaning" is established through its use, not just its content. Theodor Adorno $(1988,2006)$ takes a different approach, but prefigures Balliger's position that music's meaning and political function need not be determined through lyrics. Rather, Adorno suggests that the internal musical dynamics of a piece can and should function as a direct response to capitalism and war. That is, the power relations exercised between components of the musical material ${ }^{2}$ should respond abstractly to the power relations exercised between individuals and governance structures within the external world. Although it is important to note that Adorno's analyses are specific to certain types of Modernism, and that he judges the majority of modern music to fall short of an adequate response to the post-war Zeitgeist, his work has foreshadowed a number of ideas that are relevant to EDMCs. Walter Benjamin's essay "The Work of Art in the Age of Mechanical Reproduction" considers the effects upon the artwork's "aura" (briefly, its otherness) in light of the industrial processes associated with its production, mediation and consumption. ${ }^{3}$ Benjamin concludes that, once art is stripped of this aura through technological interventions, its cultural work becomes necessarily a matter of politics (Benjamin 1999: 235). That is, Benjamin suggests that the commodification of art, and its resultant perception as the product of labour and therefore a component of the economic system, creates an aesthetic politics - art can be seen either to reinforce or to resist power, status and authority. Simon Frith brings Benjamin's argument into the realm of popular music by suggesting that "the technology of mass reproduction [is, after Benjamin] a progressive force" (Frith 1981: 47) and that "the development of socialized means of expression enabled the development of a socialist aesthetic" (Frith 1981: 47). Moreover, the process works both ways: Jacques Attali (1985) and William S. Burroughs (2004) suggest that ideologies can be reproduced and propagated through recording technology, rendering sound a dangerous weapon in the hands of government. At the same time, music and sound are used to consolidate community: the organisation of sound "links a power center to its subjects" (Attali 1985: 6) and asserts territory against chaos through refrain and rhythm (Deleuze and Guattari 2004: 343). "With music", writes Attali, "is born power and its opposite: subversion" (1985: 6).

All this is to say that music need not contain explicit verbal references to political situations to be considered political. The way in which music is produced and used can be considered a political process in itself, reflecting and responding to the 
power relationships between anything from large international structures to individuals and machines. This process is an "aesthetic politics". This piece will explore the specific aesthetic politics of the EDMCs identified above as "rave".

\section{Aesthetic Politics: Rave Subject and Rave Object}

First, I wish to address the idea that an aesthetic politics derives from the relationships between what, for the moment, we will consider a distinct subject and object within art. By "subject", we might initially understand a creative, performing or listening self; by "object", we might mean that which the music treats or addresses, explicitly or otherwise, although these will be complicated as the argument progresses. As suggested above, the processes through which music reaches its audience have implications for its meaning. Where subject and/or object can be identified within music or culture, these are also affected by the way in which the music or culture is created, mediated or propagated.

Whilst rock musicians are often highly forthcoming about their own lives and experiences, and about what they hope to achieve, it is difficult to see who, exactly, might be the creative subject within rave, especially if we are hoping to identify a particular sociological group, a typical rave artist. The argument that rave embraced anonymity is hardly new. Haslam (1997: 177-9) and Rietveld (1998: 265) note that the subjectivity of a track's author is often subordinate to that of the DJ, who is visible and responsive in a way that the creator of a record is not. Poschardt suggests that the anonymity of the artists can be interpreted as "a transfer of authorship to music-generating technology" (1998: 286-7). With this in mind, it is not even clear at what point authorship actually occurs: popular rave tracks are often unlicensed remixes, made by DJs themselves to satisfy the needs of a specific club night (Rietveld 1997: 126), or an assembled array of illegal samples, with no marketable identity to the piece as a whole (Poschardt: 262-3). The creative dance subject fails to reside in any single ideological process.

In part, this is due to the failure on the part of any monocultural model to fit rave-goers: it is easier to decide who is speaking if we know to whom a voice is directed, and what it is saying, but Poschardt points out that

nothing in this music was designed to recall the ghettos or the Bronx or the gay clubs in Chicago and New York; it was the music of young DJs who liked house and disco and hip-hop, but were infinitely far removed from the culture of reference (1998: 263).

The suggestion that there is no ideal author or consumer within rave culture is illuminated by studies of the music itself. Reynolds goes so far as to say that the rave experience is "intransitive" (Reynolds 1997: 104), not directed to any end - rave communicates no "message" to or from any specific group of people. Gilbert and Pearson agree, arguing that attempts to narrativise or functionally explain the "non-verbal and nonrational structures of dance" have themselves been driven by an intellectual "fear of the irrational" (Gilbert and Pearson 1999: 16). Rave, here, has no basis in reality, is not a response to anything. It has no message to communicate, pursuing instead the "creation of sensations without pretext or context" (Reynolds 1997: 104; my emphasis).

Thus, the "acid test" for EDM might be considered primarily to be its success on a sonic level, as its creation of sensations, as something that sustains and develops a "vibe" (Rietveld 1998: 248; St John 2009: 97-100). The records and artists dubbed 
"electronic listening music" in the years following the rave explosion represent a significant move away from the idea that dance is a prerequisite of dance music, but warehouse parties and dance clubs grew up because there was something to gain from experiencing a beat communally. ${ }^{4}$ Where music is consumed in clubs and parties, there is no record sleeve to examine and rarely a vocalist or instrumentalist to watch: familiarity with certain tracks comes first through repeated exposure, not through promotional channels. Authorship is established through direct experience of the music, not in advance of the work itself,5 and the shared goal of surrendering to the beat (Rietveld 1998: 266) subordinates a record's origins to its effects.

All the same, identities are abstracted from the collective experience. The KLF, The Justified Ancients of $\mathrm{Mu} \mathrm{Mu}$ and The Timelords, for example, can all be identified as the work of Jimmy Cauty and Bill Drummond: the three share a highly visible anarchic approach to the values that are expected of a professional musician. Identity is problematised by the multiplicity of aliases; the navigation of the industry's own terms is rendered absurd by the publication of "golden rules" to achieve a number one single (The Timelords 1995); the KLF's doubling as a record label looks more like infiltration than complicity when it is observed that "KLF" stands for "Kopyright Liberation Front". Nonetheless, any author-identity that is established through dance music will be tempered by the constant redefinition and reinscription of that author's work. This takes place not only through samples and remixes but within the rave party itself. As part of a DJ set, music is chopped, changed and overdubbed to a utilitarian end: the best all-round experience, not the individual glory of a track. There is surely an element of competition between records, but a dance party is anything but a showcase: the identity of a track is blurred as soon as it is established. Tracks in a continuous DJ mix have no discernable beginning or end, and might be sped up, slowed down or pitch-shifted so that they are mixed seamlessly. Individuality is often secondary to compatibility.

The conclusion that the music's utility is paramount recalls Reynolds' argument that rave music's actual content does not convey any message beyond that of its own significance and signification. "The 'you' or 'it' in vocal samples refers not to a person, but to a sensation. In truth, these are love-songs to the drug... or in the case of Baby D's 'Let me be your fantasy', a love-tribute to the rave scene/dream itself" (Reynolds 1997: 107). Reynolds argues that the aesthetic politics of the rave record are static: subject and object are identified in the same place. Accordingly, there is no model to be found within rave music for its response to the world outside itself. Adorno demands that music make a response to the Zeitgeist by its very internal relationships: his analyses speak of the specific musical "material" within a piece and of the dialectic between $[S]$ ubject $^{6}$ and object (Adorno 2006). Conversely, rave's reflexivity and/or lack of object - the celebration of celebration itself - does not speak of negotiation or conflict, or even the response to stimulus.

However, to analyse an EDMC in terms of its musical texts alone is to neglect the politics of its usage: as we saw above, the records' individuality can be considered subordinate to their utility within a wider context, and the aesthetic politics of rave's wider context are anything but hermetic. Poschardt argues the point succinctly, observing that " $[\mathrm{w}]$ ithstanding and thinking through differences, and allowing them to become part of the creative process is a fundamental idea in the DJ aesthetic, in which difference is always reflected in the separateness of the two turntables" (Poschardt 1998: 295-9). This observation allows the dialectic to re-enter the discussion. However, I suggest that the rave dialectic differs from Adorno's Modernist dialectic in one 
important respect: neither turntable is considered to have primacy over the other in the way that subject confronts object. Records emerge from the mix as "crowdpleasers"; the work of one artist might become particularly well known; but these dominances are temporary. No sooner has one record been recognised than it is being mixed into another, filtered, looped, sped up or slowed down. The primacy of one record within a DJ set is an eddy, not a current. In other words, neither is identified as subject or object: the turntables are in dialogue as equals, whereas the struggle between subject and object is based on a fundamental inequality. ${ }^{7}$

Reynolds suggests that the dissolution of inequality in the rave aesthetic is driven by the deposition of Freudian hetero-normative sexual hierarchy:

One of the few truly new and "subversive" aspects of rave is that it's the first youth subculture that's not based around the notion that sex is transgressive... recoiling from our sex-saturated popular culture, rave instead locates jouissance in pre-pubescent childhood or pre-Oedipal infancy (Reynolds 1997: 106).

This is perhaps a half-truth. Reynolds' ontology is messy: the idea that the rejection of conventional sexual difference is a childlike trait suggests that adults are in fact objectively, pre-discursively sexed. Gilbert and Pearson devote some space to arguing the opposite, after Butler and Foucault: gendered and sexual norms are a product of the reproduction of discursive statements (Gilbert and Pearson 1999: 48-51), not of any "material" distinction - or, rather, there is no difference between these methods of construction. By suggesting that rave represents merely a temporary relief from an inescapable, objectively sexed adult reality, Reynolds' argument makes reference to the very degenerate ontology that the rave experience rejects. Rather, as Gilbert and Pearson go on to argue, "jouissance is a regressive experience, related to a moment in the pre-history of the subject before gendered identity is assumed" (Gilbert and Pearson 1999: 67). Although their analysis is sympathetic to Reynolds' work, the temporal language of their argument relates to the development of the idea of the [S] ubject, and not to any sexual development of the human individual.

Either way, it is a point of agreement that rave aesthetics do not discursively reproduce predetermined difference. Aided by the chemical effects of ecstasy, social and political boundaries are broken down. Wright (1998: 233) suggests that communication on the dancefloor is non-verbal, an idea echoed by Rietveld's identification of the tactile-acoustic value of collective raving (1998: 258-9). Her subsequent protest that "you could lose yourself to the beat, but this does not question the foundations of society" (Rietveld 1998: 266) might in fact be too cautious: the conceptualisation of "oneself" is precisely the foundation of society. Granted, dancing does not "question" anything, but this is because to question is to engage in discourse. Gilbert and Pearson note that "dance seems to reject discourse" (1999: 6), and it is in this quality that the rave experience offers a liberation from sexual hierarchy: not through the offer of a means to forget it, but through the refusal to accept that it is necessary at all. The dance is temporary, but there is not necessarily any limit to its psychological effects.

I therefore argue that rave's aesthetic politics are dialectical, but that the dialectic does not recognise subject as privileged over object: indeed, the internal dynamics of rave records do not recognise the two as distinct at all. Rather, rave's aesthetic politics are fluid. In rejecting the notion that difference is territorial, rave embraces the multiplicity of perspectives and cultures to which it appeals and from which it draws. Indeed, this rejection also proscribes any concrete theorisation of what rave itself is (and 
therefore what it is not), what its core beliefs might be or who its agents are. What effect, then, does this have upon rave as a site for resistance? How can something so fluid have a "voice" in protest against something so material as an Act of Parliament?

\section{Autechre and the Criminal Justice Act}

\section{http://www.youtube.com/watch?v=v4OvHLdnRI8}

Autechre - "Flutter" (Anti EP)

What is notable about the example of Anti is that the situation against which it protests is a challenge to rave itself. The Criminal Justice Act, for all its sloppy wording, intended to prohibit open-air dance parties. It made sense, then, that the associated music should have had something to say about it. Rupa Huq notes that "rave had never in its wildest... dreams come to dabble in what we have come conventionally to recognise as politics until the Criminal Justice Bill" (1999: 16). This "dabbling" represents not a (conventional) politicisation of rave itself, but rather the use of rave to a political end. The distinction might at first appear trivial but it is this resistance to becoming a point on the political spectrum that allows rave its continued utility as a political vehicle. The overt political voices that rave supplied in the period surrounding the Act were only necessary because the culture's performativity had not been a clear enough means of communication for the mass media to decode. "Rave has always been seen as primarily hedonistic, and this is reflected in its politics," suggests Huq (1999: 24). "In the face of the Bill/Act the continuation of free parties has become highly charged political rhetoric in itself" (Huq 1999: 25). The notion that these EDMCs are performative is not uncomplicated, and requires a great deal more work than can be undertaken here, but I would suggest that we begin by identifying rave as a communication: not communication by an artist to a listener, but communication by a culture regarding itself. In being its own object, rave culture itself says "rave sounds like this" or "rave makes you feel like this" or, more generally, "rave is". A rave party, or a dance record, immediately communicates its own existence to those who experience it. Where this existence is challenged, the immediate communication "rave is" becomes "rave still is".

Anti's protest, then, is its very existence. The letters "AeP" are all that is printed on the front cover; on the sleeve's sticker, they are decoded as "Agigate. educate. Protest." The verbs are imperative but self-directed, like the Dalek chant of "Exterminate!" throughout Doctor Who: the pervasive "rave is" is attached to "AeP" such that rave is redefined in the case of this particular record as an act of agitation, education and protest, and the record automatically passes into the realm of these concepts by virtue of their having been stated. The first two tracks, "Lost" and "Djarum", are identified as the "repetitive beats" targeted by the Act. ${ }^{10}$ Their very existence (at least insofar as music has to be played to exist) breaks the law - a peaceful protest, although raves are not actually "peaceful". The power of this gesture lies precisely in the fact that rave itself, and not its authorship, is the subject of the protest: authors have to do in order to break the law, whereas this music can simply be. In communicating "rave is protest", Anti protests.

In this case, the fact that rave communicates its protest "in itself" leaves its audience unaffected: the raver-subject is not drawn into the statement. Illegality does not necessarily politicise the very rave experience - Rietveld notes that "losing one's ego to relentless machine rhythms... does not seem to create a strong counter-political force" 
(1998: 259) - but is sufficient to enable it to be read politically. Even after it is placed into the political spectrum, it fails to be bound there. It can be used but never used up.

Autechre's commentary reflects this. "Autechre is politically non-aligned," read the Anti sleevenotes. "This is about personal freedom". The suggestion here is not that Sean Booth and Rob Brown have no political leanings. Rather, Anti asserts that Autechre as an artistic vehicle cannot be politically aligned because EDMCs are multiple and the music is constantly anonymised, reclaimed and reinscribed. Electronic dance music, suggests Anti, does not and cannot adhere to a party political manifesto.

It is important to note that the EP does not claim to be non-political. The overall impression of the project is quite the opposite. Rather, what is rejected by this particular sleevenote is a politics that locates personal freedom on a left/right scale, or by which music is circumscribed by its motivation. ${ }^{11}$ The analysis begins to look almost anarchic - not so much "after" politics as "before" them, with personal freedom a precondition of political reasoning. Autechre's assertions are a little problematic in respect of the performativity argument because it is not the music's authors who are performing the illegal speech-act but the music itself. By invoking their own authorship, Autechre in fact link Anti to a much older creator/created binary that seems a little at odds with rave culture's relentless refusal to be authored - either way, it remains that Anti's very existence as "repetitive beats" rejects the terms upon which the legal system tries to regulate the use of music.

\section{The Justified Ancients of Mu Mu and the Politics of Sound}

http://www.youtube.com/watch?v=-eqCa5RnGuM

The Justified Ancients of Mu Mu - "All You Need Is Love" (1987)

Jimmy Cauty and Bill Drummond's records are characterised by an intensive examination of the conventions and restrictions associated with music, and a focus on the diffculty of resisting them. In 1987, they issued an album (1987: What the Fuck's Going On?) whose samples were all unlicensed. In treating the original texts in such a way that they were not only decontextualised but made to look absurd, they turned violent the rave aesthetic of inclusiveness. In a move almost reminiscent of Christ's Sermon on the Mount, they made it clear that neither The Beatles nor ABBA nor Dave Brubeck was any more "important" than the Scottish voice shouting "shag! shag! shag!".

The idea that cutting up recorded sound is a means to redistribute power owes much to Burroughs. In The Ticket That Exploded, he suggests that the news media (and, by implication, any other filtration of information) influences the wider world more through its treatment of "sounds" and "voices" than through the actual content of these sounds and voices themselves:

look around you look at a control machine programmed to select the ugliest stupidest most vulgar and degraded sounds for recording and playback which provokes uglier stupider more vulgar and degraded sounds to be recorded and play back inexorable degradation... look forward to ugly vulgar playback tomorrow and tomorrow and tomorrow what are newspapers doing but selecting the ugliest sounds for playback by and large if it's ugly it's news (Burroughs 2004: 339)

At the same time, he proposes a reclaiming of language through the revealing and reversal of these techniques: 
only way to break the inexorable down spiral of ugly uglier ugliest recording and playback is with counterrecording and playback... the more you run the tapes through and cut them up the less power they will have cut the prerecordings into air into thin air (Burroughs 2004: 340)

The "voices" can be overcome by wresting control away from the controllers. To manipulate the artefacts of a dominant culture ("speed up slow down play backwards inch the tape") is to turn these artefacts against their creators: cutting up language reveals that the "control machine" can never fully control it at all. This is not only true of words. The JAMs appropriated not just the recordings of other artists, but also their very artistry itself: through the same process by which ABBA and The Beatles had constructed identity, it was dispersed and reassigned. "We hereby liberate these sounds from all copyright restrictions, without prejudice”, read the centre label of the 1987 LP. That they could be liberated in this way at all questions whether they were ever truly bound by copyright legislation: The JAMs successfully challenged the ownership of these sounds for long enough for the challenge to enter collective memory (some 23 years later, we are still writing about it), and they did so with no opposition until after the horse had bolted. Without totally prohibiting access to all of their recordings in any form, there is no way that ABBA could have controlled the usage of these recordings - but to prohibit access in this way would be to erase the music completely, because even its existence in memory would enable its later appropriation (through covering, writing down, discussion, and so on). By existing on vinyl, the sounds were quite literally there for the taking. As Deleuze and Guattari reflect on the idea that music does not remain objectively linked to its stimulus but enters into continuous variation and becomes autonomous (Deleuze and Guattari 2004: 353), The JAMs made an aesthetic-political gesture by asserting that sound could never be "owned". The gesture was not well received: the legal system was quickly on hand to reassert the older values on behalf of those whose "property" had not been licensed through the correct channels. An injunction from ABBA's lawyers ordered the recall of all unsold copies of 1987.

The eventuality for which the legal system did not appear to have planned was that rave's anti-commercial aesthetic would be quite so well served by its oppression (Hemment 1997: 213). By attempting to smother The JAMs' protest against artistic norms, the legal system made these norms look totalitarian and desperate. The JAMs' success should not be evaluated by their susceptibility to the power structures they challenged, but by their invocation of the power of sound itself. Not all copies of 1987 were destroyed, and, either way, the point had already been made to the "control machine". ${ }^{12}$ Not only this: their later issue of an EP-length version of 1987 that lacked all the illegal samples politicised the very absence of sound.

In short, the JAMs made the protest that sound was power by using sound itself; the truth of their argument was manifest and immediate. It is undeniably awkward to describe as a "speech-act" something that seems by its very constitution to deny order, but I propose that the model of a performative protest is useful here, too. Although 1987 was, in fact, authored, my suggestion is not that The JAMs performed a speechact through its creation but that 1987 communicates its own disruptive influence. That is, the album itself exerts a political force. By communicating that "sound cannot be owned" through the recordings of other people, it substantiates its own point: ownership is flux, because it relies upon the assertion of power, and power is necessarily in constant flux. ABBA's injunction did not mean that ABBA did, in fact, "own" the 
music after all; it meant that they had more financial and legal power than The JAMs. However, these factors are changeable: were ABBA, for example, to lose all their money - or to die - they would no longer be able to exert such power. Accordingly, the power would remain in the hands of the recording, deterritorialising "Dancing Queen" and the word "shag" indefinitely. Once it is revealed that authorship is contingent, not absolute, the ownership of sound becomes moot. Any action asserts power at one particular time, but sound betrays its creators the moment it is created (Barthes, of course, made this point): to continue to assert control over its use after this moment, as is currently privileged by legislation, is not a right but a contingency.

What implications does this have for rave? It might be suggested that Anti performs a similar function to 1987: it fails to submit to regulation, and by so doing reveals that power can be resisted or reclaimed by an action so seemingly apolitical as dancing or making abstract electronic music. By its internal dynamics, rave recognises power relationships as flux, not hierarchy. The assertion of absolute dominance is antithetical and meaningless.

\section{Conclusion: the Aesthetics of the Rave Protest}

The central argument of this study has been that rave's very existence is an automatic, even a pre-emptive protest against anything that tries to restrict it. I have suggested, firstly, that rave rejects attempts to categorise or dominate it because its aesthetic politics are fluid. There is no model within its internal dynamics for subordination, only for dialogue on equal terms, so it is not ideologically equipped to be "beaten". Secondly, I have argued that, by using its own apparatus - the production and use of music - as the currency of its protest (as opposed, for example, to writing a letter, or committing acts of terrorism), rave squares up to power structures on its own terms. Through artefacts such as 1987 , or the continuation of unlawful dance parties, it communicates that it does not recognise attempts to control it. It refuses to cease and desist. It has been concluded that, by so doing, rave reveals power to be just as fluid and impermanent as its own aesthetics: this party can be broken up, that record can be banned, but neither party nor record can actually un-happen, and no power structure can be truly omnipotent, so new gestures will (or, rather, could) always be forthcoming. The use of actual or threatened physical force is enough to disperse specific rave gatherings on a physical level, but a culture that does not recognise absolute concepts can never be permanently defused. Similarly, as noted at the beginning of this piece, "rave" is amorphous, referring to any number of EDMCs in constant flux - and so "it" can never be conquered. Attempts to regulate it only prove the point: regulation is temporary and the right to exert it is contingent. One is reminded of the child who signs an offensive graffito with the words "if destroyed, forever true". Attempts to silence rave have only made it louder.

\section{Acknowledgments}

I am grateful to Graham St John, whose patient, constructive feedback was invaluable to the development of this article. Thanks are also due to Simon Warner at the University of Leeds for his support with the original version of the piece. 


\section{References}

Adorno, Theodor W. 1988 [1955]. "The Aging of the New Music." Trans. Robert HullotKentor. Telos 77: 95-116.

----. 2006 [1949]. Philosophy of New Music. Trans. Robert Hullot-Kentor. Minneapolis: University of Minnesota Press.

Attali, Jacques. 1985 [1977]. Noise: The Political Economy of Music. Trans. Brian Massuimi. Manchester: Manchester University Press.

Balliger, Robin. 1999. "Politics". In Bruce Horner and Thomas Swiss (eds), Key Terms in Popular Music and Culture, pp. 57-70. Oxford: Blackwell.

Beadle, Jeremy J. 1993. Will Pop Eat Itself?: Pop Music in the Soundbite Era. London: Faber and Faber.

Benjamin, Walter. 1999 [1935]. "The Work of Art in the Age of Mechanical Reproduction". In Hannah Arendt (ed), Illuminations, pp. 211-44. Trans. Harry Zorn. London: Pimlico.

Burroughs, William S. 2004 [1968]. "The Invisible Generation”. In Christoph Cox and Daniel Warner (eds), Audio Culture: Readings in Modern Music, pp. 334-40. London: Continuum.

Deleuze, Gilles and Félix Guattari. 2004 [1980]. A Thousand Plateaus: Capitalism and Schizophrenia. Trans. Brian Massumi. London: Continuum.

Doggett, Peter. 2007. There's a Riot Goin' On: Revolutionaries, Rock Stars and the Rise and Fall of '60s Counter-Culture. Edinburgh: Canongate.

Evans, Dylan. 2001. Emotion: A Very Short Introduction. Oxford: Oxford University Press.

Frith, Simon. 1981. Sound Effects. New York: Pantheon.

Garofalo, Reebee (ed). 1992. Rockin' the Boat: Mass Music and Mass Movements. Cambridge, MA: South End Press.

Gilbert, Jeremy and Ewan Pearson. 1999. Discographies: Dance Music, Culture and the Politics of Sound. London: Routledge.

Haslam, Dave. 1997. “DJ Culture”. In Steve Redhead et al. (eds), The Clubcultures Reader, pp. 169-79. Oxford: Blackwell.

Hemment, Drew. 1998. "Dangerous Dancing and Disco Riots: The Northern Warehouse Parties". In George McKay (ed), DiY Culture: Party and Protest in Nineties Britain, pp. 20827. London: Verso.

House of Commons. 1994. Criminal Justice and Public Order Act. <http://www.opsi.gov.uk/ acts/acts1994/Ukpga 19940033 en 1.htm> (accessed 15 March 2008).

Huq, Rupa. 1999. "The Right to Rave: Opposition to the Criminal Justice and Public Order Act 1994". In Tim Jordan and Adam Lent (eds), Storming the Millennium: The New Politics of Change, pp. 15-33. London: Lawrence \& Wishart.

Porschardt, Ulf. 1998. DJ Culture. London: Quartet.

Reynolds, Simon. 1997. "Rave Culture: Living Dream or Living Death?" In Steve Redhead, Derek Wynne and Justin O'Connor (eds), The Clubcultures Reader, pp. 102-11. Oxford: Blackwell.

Rietveld, Hillegonda. 1997. “The House Sound of Chicago". In Steve Redhead, Derek Wynne and Justin O'Connor (eds), The Clubcultures Reader, pp. 124-36. Oxford: Blackwell.

----. 1998. "The Politics of Contemporary DiY Dance Culture”. In George McKay (ed), DiY Culture: Party and Protest in Nineties Britain, pp. 243-67. London: Verso.

St John, Graham. 2009. Technomad: Global Raving Countercultures. London: Equinox.

Timelords, The. 1995 [1988]. “The Golden Rules". In Hanif Kureishi and Jon Savage (eds), The Faber Book of Pop, pp. 273-7. London and Boston: Faber and Faber.

Wright, Mary Anna. 1998. “The Great British Ecstasy Revolution”. In George McKay (ed), DiY Culture: Party and Protest in Nineties Britain, pp. 228-42. London: Verso. 


\section{Mediography}

Autechre. 1994. Anti EP. Warp Records (12-inch): WAP 54. http://discogs.com/release/157 Justified Ancients of Mu Mu, The. 1987. 1987: What the Fuck's Going On? The Sound of $\mathrm{Mu}(\mathrm{sic}) / \mathrm{KLF}$ Communications (LP): JAMS LP1. http://discogs.com/release/140785

----. 1987. 1987: The JAMs 45 Edits. The Sound of Mu(sic)/KLF Communications (12inch): JAMS 025T. http://discogs.com/release/55367

Justified Ancients of Mu Mu, The, Disco 2000 and The Timelords. 1988. Shag Times. The Sound of $\mathrm{Mu}(\mathrm{sic}) / \mathrm{KLF}$ Communications (2xLP): JAMS DLP3.

http://discogs.com/release/160230

\section{Author Biography}

Ramzy Alwakeel was born in 1988 in the East Midlands of England. He holds a Bachelor's degree in Music from the University of Leeds, and will begin a Master's in Newspaper Journalism later this year. His article "IDM as a 'Minor' Literature" appeared in the inaugural issue of Dancecult in September 2009.

\section{Notes}

1 See Gilbert and Pearson (1999: 54-83); "voice" is of particular significance to their examination of the alleged split between rock music and dance music.

2 This is particularly pertinent to the analysis of serialism (especially integral serialism), within which parameters such as tone row, duration, dynamics and form are "generated" by parallel mathematical processes.

3 The essay primarily addresses silent cinema, but Benjamin's argument can be extrapolated in light of the technologies and industries that have developed since. This is problematic, since Benjamin considers the medium of silent film utterly distinct in its effects from that of film with a recorded soundtrack, so we should not be too quick to assume that the work is applicable to anything that is reproducible. Nonetheless, as Frith points out (see below), the limitations that Benjamin himself imposes need not be considered absolute given that so much has changed about the culture industry since 1935 .

4 See Rietveld (1998: 258-9), who makes reference to the "tactile-acoustic" component of EDMC, for example.

5 Artists will sometimes produce "white-label” records that bear no written details whatsoever, making this effect even more explicit. To some extent, the use of an alias also enables this focus away from authorship, but it is equally the case that debate around the "true" identity of an artist can become central to a record's publicity. One is reminded of the debate in 2008 around Rephlex Records' "new" dance artist The Tuss, which is almost certainly Richard D. James.

6 Adorno refers to "the Subject", where the capital "S" denotes a much wider-reaching selfhood that is common to, or arises from, collective humanity. The concept differs from that of "the first person", which refers only to the individual, although the two are related by their invocation of the "I". It might be suggested that the subject is the protagonist in his/her own life, while the Subject is the collective protagonist in the world. 
7 The DJ, of course, might be considered subject to the music's object, but we are primarily concerned here with auditory relationships between the records themselves. Nonetheless, in a different analysis, the DJ is the primary subjective figure within the rave experience, manipulating recorded music as an instrumentalist manipulates the instrument. All the same, this DJ/DJ-ed power relationship is perhaps less central to the rave experience than that of the instrumentalist over the instrument for the reason that the DJ is not the focus of the rave experience, even if $s /$ he might be one of its architects. As noted elsewhere, rave celebrates the rave experience itself: sensations, not their causes, are its primary interest. See Evans (2001: 75), who describes rave as "the ultimate short cut to happiness". The language of short cuts and immediacy suggests that end (sensations derived from the rave experience) is more important than means (DJ, discs, drugs, event organisers, etc.).

Bearing in mind that rave does not embrace any absolute theorisation of its own unique selfhood, it might be more accurate to suggest that the communication is in fact "right now, to you, rave sounds/feels/is like this". For brevity, I will continue to refer to the shorter version.

9 Elsewhere in Autechre's catalogue, "Ae" abbreviates Autechre, with "AeP" reflecting the recurring production credit on Autechre's artwork: "Autechre Production" appears at the beginning of the label copy for Anti itself. By Tri Repetae the following year, the phrase had in fact decayed into "Ae Production", in which form it has appeared on every release since.

10 Obviously, Autechre will have been under no illusions about the legal impotence of the musicology argument regarding "Flutter": all three of the tracks on the EP would have been perceived as contravening the Act.

11 To experience Anti as music is not necessarily to engage with the political implications of its use in 1994; to be physically allowed to experience Anti at all, however, is a prerequisite for its use in any context.

12 Beadle muses that "I wonder now whether The JAMs really cared about saving the album - after all, they'd done it and that was that" (1993: 111). 